\title{
Special Issue on Geostatistics for Environmental Applications
}

\author{
Amilcar Soares
}

Published online: 8 January 2009

(C) International Association for Mathematical Geosciences 2009

"Standards of living are fundamentally related to how much knowledge we have of how to use the World's resources. It is very clear that the complexity of the World is such that our ability to actually forecast is limited by our inability to see all the ramifications of the various permutations and combinations"

Alan Greenspan (former chairman of the US Federal Reserve)

Until the early 90 s of the last century, environmental applications of geostatistics did not share the same shining stage as the mining and petroleum applications. In some way, the small number of papers in international conferences and researchers involved in the field reflected the concern and priority level that the society and the scientific community devoted to the environmental problems. On the other hand, the dominant mainstream of methods for approaching these problems-qualitative paradigms of analyzing natural resources (e.g., forest, biodiversity, soil), deterministic modeling for characterizing environmental issues (e.g., air pollution, climate, groundwater), statistical methods that did not privilege the space-time component of those phenomena-did not contribute much for changing this scenario.

During the 90s, environmental problems like ozone depletion, greenhouse effect, global warming, loss of biodiversity, desertification and drought became global and public issues, changing the environmental risk perception of people radically. The United Nations conferences and summits, from Rio (1992) to Kyoto (1997), definitively pushed those points towards most countries' agenda, leading to significant investments in research and development. Hence, the applications of quantitative methods (particularly in geostatistics) to monitor, manage, remediate and mitigate environmental resources became an appealing challenge for

A. Soares $(\bowtie)$

CERENA, Instituto Superior Técnico, Lisboa, Portugal

e-mail: asoares@ist.utl.pt 
the geosciences community. Since then geostatistics applied to environment has grown significantly: reference books have been published by authors with an expertise out of the mineral resources field (Goovaerts 1997; Wackernagel 2003; Webster and Oliver 2007); Geostatistics international conferences (Soares 1993; Dimitrakopoulos 1994; Baafi and Scholfield 1997; Kleingeld and Krige 2001; Leuangthong and Deutsch 2005) have shown a significant increase of papers on environmental applications. Environment itself became the topic of international conferences: a series of geoENV_-geostatistics for Environmental Applications-born in Lisbon in 1996 (Soares et al. 1997) and has been held every two years in Europe (Gomez-Hernandez et al. 1999; Monestiez et al. 2001; Sanchez-Villa et al. 2003; Renard et al. 2005; Soares et al. 2008).

This special issue intends to highlight this moment of this application field of geostatistics and to honor, in particular, the ten years of the geoENV conferences. For this purpose, authors of selected proceedings papers of geoENV conference in Rhodes (Soares et al. 2008) were invited to write modified and extended versions of their manuscripts for a special issue of Mathematical Geosciences. Five of these contributions, each representing one of the following areas of groundwater, soil, environmental health, applications of remote sensing in environmental field and climate, have been accepted and are presented in this issue.

In the first paper, Pierre Goovaerts presents the last developments of a very recent field of geostatistical applications: Medical Geography. Impact risks of pollutant contamination on human health are dealt with geostatistical methodologies of kriging and stochastic simulations, in a specific framework where data is typically aggregated over irregular spatial supports and related with socio-economic covariates.

Satellite remote sensing images are most promising tools for earth and environment observation. They are not only indicated for assessment of phenomena with a considerable wide extension, such as desertification and air pollution, but also for environmental monitoring of developing countries that lack the resources for field data. One of the most important challenges of geostatistics in this field is precisely related with the limitation of those images: spectral and spatial resolutions. Alexandre Boucher presents recent geostatistical methods for downscaling the spatial resolution of images by coupling bi-point and multi-point statistics.

Climate is definitively one of the most critical environmental problems of our times. Uncertainty attached to the related models and data are among major issues of this field. Climatic data taken at different historical periods with different technologies are very often noised by non-climatic factors, which can lead to erroneous and biased conclusions of an observed climatic phenomenon. Hence, climatic data needs to be homogenized before it is fed to models. Costa et al. use conditional simulations to deal with the homogenization of climatic data. This paper reviews the characteristics of several widely-used homogenization procedures, and discusses the potential advantages of stochastic simulation techniques.

Soil degradation and the lack of clean water are turning these resources more and more valuable and critical, making their preservation an environmental obligation. Although they are not yet adopted by the mainstream of industrial applications, geostatistics has given robust and accurate answers to the solution of monitoring and characterization of contaminated sites. Dimitri D'Or et al. present a geostatis- 
tical methodology to estimate multiple correlated soil contaminants, dealing with the change of support when confronted to various regulatory thresholds.

Evaluation of vulnerability risk and impact analysis of extreme values is also an issue on the transport of reactive solutes in heterogeneous aquifers. Sanchez-Vila et al. proposes the estimation of the probability density functions of concentrations, at any point in space-time referential, opening the door for potential new tools for hydrogeologists to approaching this type of problems.

We hope that this small sample of topics of environmental problems that now are being addressed with geostatistical methods will attract scientists and practitioners for the new and urgent challenges that Environment and Natural Resources are facing in our times.

\section{References}

Baafi E, Scholfield N (eds) (1997) Geostatistics Wollongong'96, vols 1 and 2. Kluwer Academic Publishers, Dordrecht

Dimitrakopoulos R (ed) (1994) Geostatistics for the next century. Kluwer Academic Publishers, Dordrecht

Gomez-Hernandez J, Sosres A, Froidevaus R (eds) (1999) geoENV II-Geostatistics for environmental applications. Kluwer Academic Publishers, Dordrecht

Goovaerts P (1997) Geostatistics for natural resources characterization. Oxford University Press, London

Kleingeld W, Krige D (eds) (2001) Geostatistics 2000 Cape Town, vols 1 and 2. Geostatistical Association of South Africa

Leuangthong O, Deutsch C (eds) (2005) Geostatistics Banff 2004, vols 1 and 2. Springer, Dordrecht

Monestiez P, Allard D, Froidevaux R (eds) (2001) geoENV III-Geostatistics for environmental applications. Kluwer Academic Publishers, Dordrecht

Renard P, Demongeot H, Froidevaux R (eds) (2005) Geostatistics for environmental applications. Springer, Dordrecht

Sanchez-Villa X, Carrera J, Gomez-Hernandez J (eds) (2003) geoENV IV-Geostatistics for environmental applications. Kluwer Academic Publishers, Dordrecht

Soares A (ed) (1993) Geostatistics Troia'92, vols 1 and 2. Kluwer Academic Publishers, Dordrecht

Soares A, Gomez-Hernandez J, Froidevaux R (eds) (1997) geoENV I-Geostatistics for environmental applications. Kluwer Academic Publishers, Dordrecht

Soares A, Pereira MJ, Dimitrakopoulos R (eds) (2008) geoENV VI-Geostatistics for environmental applications. Springer, Dordrecht

Wackernagel H (2003) Multivariate Geostatistics: an introduction with applications, 2nd edn. Springer, Berlin

Webster R, Oliver MA (2007) Geostatistics for environmental scientists (statistics in practice), 2nd edn. Wiley, New York 